\title{
Tackling grand challenges beyond dyads and networks: Developing a stakeholder systems view using the metaphor of ballet
}

\author{
Thomas J. Roulet \\ t.roulet@jbs.cam.ac.uk \\ University of Cambridge \\ Joel Bothello \\ joel.bothello@concordia.ca \\ Concordia University
}

Forthcoming at Business Ethics Quarterly

\begin{abstract}
:
Tackling grand challenges requires coordination and sustained effort among multiple organizations and stakeholders. Yet research on stakeholder theory has been conceptually constrained in capturing this complexity: existing accounts tend to focus either on dyadic level firm-stakeholder ties, or on stakeholder networks within which the focal organization is embedded. We suggest that addressing grand challenges requires a more generative conceptualization of organizations and their constituents as stakeholder systems. Using the metaphor of ballet and insights from Dance Theory, we highlight four defining dimensions of stakeholder systems (two structural and two dyadic); we proceed to offer a dynamic model of how those dimensions may interact and co-evolve. Our metaphor and resulting theory of stakeholder systems are thereby well-equipped to incorporate the complexity of tackling grand challenges, where many contemporary stakeholder arrangements are oriented around issues rather than firms.
\end{abstract}

Keywords: Stakeholder theory; Systems; Dance; Ballet; Networks.

Acknowledgements: We are grateful for the feedback we received from our editor Bruce Barry and three anonymous reviewers. We also thank Bertrand Valiorgue, Emilie Bourlier-Bargues, Lionel Garreau, and participants of the April 2021 research seminar at Université Paris Dauphine on systems theory. 
"Poverty reduction [is] at the top of the global agenda [and has] reshaped policy priorities, galvanizing the attention and interest of governments, international organizations, the private sector, and individuals.... We are in search of a truly global partnership for development [where] 'convergence' must be an overarching principle. At the same time, we need to allow for differences in the pace and rhythm of getting there."

Pascal Lamy, former Director-General of the WTO (2013)

Tackling grand challenges such as poverty, climate change, modern slavery, political instability - and more recently, the COVID-19 pandemic - have required, and continue to require, sustained collaborative efforts from an array of diverse stakeholders (George, HowardGrenville, Joshi, \& Tihanyi, 2016). Towards this end, private, state, and transnational actors such as the UN, the World Bank, the International Labour Organization (ILO) and the World Health Organization (WHO) have set overarching goals and launched programs aimed at tackling such challenges, ranging from the Sustainable Development Goals (SDGs) to the Paris Agreement and COVAX ${ }^{1}$. As a result of these initiatives, stakeholder practices have advanced considerably, with numerous novel and sophisticated arrangements for mobilizing multiple actors towards a common goal (Abbott, 2012, 2013; Hargrave, 2009; Ostrom, 2010).

Stakeholder theory, on the other hand, has arguably not kept sufficient pace in examining the dynamics of these stakeholder arrangements that organize around issues rather than firms. We attribute this to implicit conceptual premises in existing accounts: firmstakeholder relationships are represented through the image of either a "hub-and-spoke" wheel - i.e. a collection of dyadic interactions (Freeman, 1984; Mitchell, Agle, \& Wood, 1997) - or as a "web", where the firm is a central node within a larger stakeholder network (Rowley, 1997; Werhane, 2011). Although not without their contributions, such images contain considerable limitations for understanding how multiple stakeholders coordinate around grand challenges. For one, organization-stakeholder ties and the overall network structure are in a dynamic and

\footnotetext{
${ }^{1}$ An initiative between the WHO and Gavi (a private vaccine alliances) to ensure equitable distribution of the coronavirus vaccine
} 
co-constitutive relationship: for instance, as firms learn about and adapt to changing stakeholder demands (Girard \& Sobczak, 2012), those relationships are likely to evolve, with incremental changes accumulating into substantive transformations of the entire structure (Bothello \& Salles-Djelic, 2018). Furthermore, these perspectives do not adequately capture other important characteristics of stakeholder systems, such as the functions or roles of different actors, the emergent properties of stakeholders organizing together, or the teleology (i.e., aims and goals) of the overall arrangement. To wit, dyadic- and network-based images are not geared towards viewing the whole as more than the sum of its stakeholder parts.

We propose therefore, that in order to understand how actors address grand challenges, we require a novel conceptualization of firms and their stakeholders as stakeholder systems. We derive the term from General Systems Theory (von Bertalanffy, 1968), a perspective that views social systems as comprised of interrelated and interdependent components that function together as a cohesive whole. This conceptualization is suited for both detailed scrutiny of relationships and holistic views of the whole system (von Bertalanffy, 1972); in other areas of management literature, the systems view has been highly useful in helping us understand phenomena such as interorganizational relationships, managerial goals, organizational structure (Kast \& Rosenzweig, 1972; Shipilov \& Gawer, 2020; Van de Ven, 1975) but also more directly business sustainability (Bansal, Grewatsch \& Sharma, 2021).

Thus far, however, a systems-level perspective in stakeholder research has been surprisingly absent, despite a more recent renewed interest in organizational systems theory more broadly (Adner, 2017; Shipilov \& Gawer, 2020). The sparse handful of accounts that we do have are often limited to a cursory observation that firms and their stakeholders are interdependent (Schilling, 2000; Werhane, 2008, 2011). We therefore have yet to explore other, equally important implications of stakeholder behavior within a systems perspective, such as teleology (i.e., the articulated goals or problems driving action) or the narratives that collectively drive actors towards a common goal. Importantly, we have yet to fully flesh out 
the potential of a systems view to simultaneously conceptualize the dynamic interactions between inter-organizational relationships (Kilduff \& Brass, 2010) and the overall stakeholder collective (Welcomer, Cochran, Rands, \& Haggerty, 2003). Our goal, in this piece, is to take an explanatory approach to theorizing (Cornelissen, Höllerer, \& Seidl, 2021: 6) and "establish the fundamental processes and structures that 'underlie' and therefore explain" the dynamics of stakeholder systems.

We therefore seek to advance a stakeholder systems view using reasoning by metaphor (Cornelissen, 2005, 2006), drawing insights from ballet choreography. We argue that stakeholders in a system and around a focal organization behave as dancers on a stage: despite having their own roles, functions and purposes, the actors are interdependent and coordinate to produce a performance (Harrison \& Rouse, 2014). In addition, as with other systems, ballet performances are comprised of properties such as teleology, interdependence and storytelling; as such, they contain elements that are absent from competing dyad and network-based accounts. Our metaphor thereby provides the basis for a "semantic leap" (Cornelissen, 2006: 1584) that generates new ways of making sense of organizations and their contexts by drawing parallels with other phenomena (Cornelissen, 2005; Ketokivi, Mantere, \& Cornelissen, 2017).

In our case, we propose that ballet (the source domain) is useful for analyzing and explaining how firms and stakeholders respond to grand challenges (the target domain) in a manner that other metaphors do not sufficiently capture. The focus of dance on "acting, watching and feeling more than verbalizing and listening" (Hanna, 1987: 18) therefore offers fertile terrain for novel conceptualizations requiring action, aesthetics, timing and dynamism, especially in management studies where theorization is mainly drawn from language-based metaphors (Bitektine, Haack, Bothello, \& Mair, 2019). Dance therefore offers a rich context for theorizing about how organizations and stakeholders coordinate, especially in light of grand challenges. 
To inform our metaphor, we select seven iconic ballet performances from four subgenres: classical (Swan Lake, The Nutcracker), romantic (La Sylphide, Giselle), neoclassical (Apollo) and contemporary (Clytemnestra, Isadora). We use dance theory - a framework used by choreographers to produce choreographies and partner interactions that are both harmonious and meaningful (Daly, 1994; Hanna, 1987; Biehl, 2007; Kodo, 2015) - to define four axes that capture major points of choreographic variance. In doing so, we also capture some fundamental ways stakeholder interactions and arrangements co-evolve. Two axes (narrative and coherence) are based on ensemble distinctions across our sample of ballets, and therefore reflect characteristics at the level of the stakeholder collective. The remaining two (interactions and balance) reflect relational characteristics between the principal dancer and partners, and therefore parallel firm-stakeholder dyadic ties. Aside from allowing a discussion of how the two levels are co-constitutive (Archer, 1995; Barley \& Tolbert, 1997), these characteristics generate insight regarding the evolution of stakeholder systems over time.

The rest of the article proceeds as follows: we first take stock of how stakeholder theory has moved beyond the limits of dyadic interactions (Margolis \& Walsh, 2003), but also highlight the constraints of recent network-based accounts. We then outline the advantages of a stakeholder systems approach, as well as the merits of ballet as a metaphor. We proceed to expose the specific cultural objects under study: seven ballets across four types of choreographic styles, using dance theory as a bridge between the domain of origin (ballet) and the target domain (stakeholder theory). Consequently, we develop our metaphor and flesh out the characteristics of stakeholder systems. We finally use this framework to theorize some dynamics of stakeholder systems, proposing two paths along which a system might evolve. Finally, we discuss how ballet and a stakeholder systems view brings a unique perspective to stakeholder management, especially in addressing grand challenges. 


\section{The "hub and spoke" metaphor: Early dyadic perspectives}

Stakeholders are defined as groups or individuals that have a direct or indirect relationship (whether based on interest, interdependence or power) with a focal actor, generally the firm. Initially formalized through the seminal work of Freeman (1984; see also: Freeman, Harrison, Wicks, Parmar, \& De Colle, 2010; Freeman, Harrison, \& Zyglidopoulos, 2018), early perspectives on stakeholders sought to identify and catalogue the major groups of actors that could affect (or be affected by) a firm - for example customers, employees, suppliers, the media or governments. This understanding consisted of a "hub-and-spoke" image of ties between the focal firm and stakeholders that was, by construction, dyadic. Subsequent research elaborated upon this metaphor, highlighting how, for instance, two actors within the same stakeholder group could potentially have different relationships with the focal firm (Bridoux \& Stoelhort, 2014; Shymko \& Roulet, 2017). Instead of simply defining which stakeholders "counted" (Dawkins, 2015), management theorists focused on the characteristics that made them salient to a focal actor (Mitchell et al. 1997; Neville et al. 2011).

Since then, stakeholder theorists have sought to reveal how firms may most effectively react to the pressures they face from stakeholders (Frooman, 1999). For example, instrumental stakeholder theorists propose that organizations build a "relational ethics strategy" that is based on either communal relationships or more transactional- and market-oriented exchanges (Bridoux \& Stoelhorst, 2016; Jones, Harrison, \& Felps, 2018). Both perspectives have implications for where the firm should position itself in its relationship with its constituents for efficient stakeholder management but are still, at their core, based on Freeman's hub-and-spoke image. The perspectives subsequently fall short in considering how stakeholders connect with or through each other, independently from their link with the focal firm. As Rowley (1997: 890) notes, "each firm faces a different set of stakeholders, which aggregate into a unique pattern of behavior". Accordingly, more recent contributions have proposed an alternate metaphor of a 
"web" (Welcomer et al., 2003), in other words a network reconceptualization of stakeholder arrangements.

\section{The "web" metaphor of networks: conceptual merits and limitations}

Network research emphasizes the importance of going beyond dyads (Kilduff \& Brass, 2010; Burt, et al., 2013; Tasselli \& Caimo, 2019) based on two observations of stakeholder behavior: (i) the influences of different stakeholders over a focal actor necessarily overlap and interact with each other (Frooman, 1999) and (ii) the salience of a stakeholder to a focal organization is not necessarily direct because intermediary parties mediate the relationship with and among stakeholders (Neville et al., 2011; Roulet, 2020). Network characteristics such as social capital (Cots, 2011; Okazaki, Plangger, Roulet, \& Menéndez, 2020) are therefore important considerations for understanding stakeholder arrangements: Rowley (1997), for instance, proposes that the density of the stakeholder network surrounding an organization leads to increased pressure while the organization's centrality enables more resistance to this pressure. The network perspective therefore offers important explanatory power: Hein et al. (2017), for example, consider how organizational goals are potentially achieved not only through resource provision and exchange between the firm and stakeholders, but also through facilitating exchanges among stakeholders themselves.

However, while a network image has proven generative for understanding stakeholders as part of a broader web, there are numerous conceptual shortcomings, in particular with capturing the dynamism of stakeholder arrangements. This omission is important for multiple reasons: first, dyadic relationships and structure are interrelated and co-evolve. Bothello and Mehrpouya (2018), for instance, illustrate how one intermediary actor shapes the field of urban sustainable development through its dyadic relationships with standard-setters, which carries implications for all other actors within the field. Secondly, the trajectory of co-evolution of dyad and structure may be underpinned by teleological factors that are not captured by a 
network view, for instance when actors coalesce to deal with larger problems. In an illustrative case, Haas (1989) shows how clean-up of pollution in the Mediterranean occurred through epistemic communities where actors were, in many cases, disconnected from each other. Thirdly, a network perspective is not geared towards conceptualizing temporal dynamics with stakeholders such as rhythm and pace, for instance the frequency of firm announcements to stakeholders or the timing of environmental investments (Bowen, Johnson, Shevlin, \& Shores, 1992; Nehrt, 1996). Fourth, and crucially, understanding network characteristics does not aid in assessing the appropriateness of how stakeholders coordinate to achieve a goal.

These conceptual constraints inhibit exploration of many recent empirical phenomena, especially around how stakeholders coalesce around addressing grand challenges (George et al., 2016). For instance, multi-stakeholder initiatives (MSIs) such as the Roundtable for Sustainable Palm Oil (RSPO), the Forest Stewardship Council (FSC) or the Marine Stewardship Council (MSC) are constructed around a specific environmental problem and involve a variety of parties that coordinate to collectively create responsible behavior (Mena \& Palazzo, 2012; Moog, Spicer, \& Böhm, 2015). Members of such initiatives are considered stakeholders of an issue rather than of an organization (Saffer, 2019). Yet, in focusing on nodes and ties, a network perspective contains certain blind spots: the moral legitimacy of MSIs, for instance, is treated as the outcome of stakeholders being tightly or loosely coupled to each other (Rasche, 2012), when legitimacy may in fact serve as an antecedent rather than consequence of network structure.

These omissions therefore require a different perspective on stakeholder arrangements. A revised conceptualization would ideally retain the strengths of the network view in analyzing the structural arrangement of stakeholders while also incorporating the analytical depth of studying dyadic links. It would also potentially shift away from reifying the organization as the focal actor, and instead consider how social actors act as a collective towards solving a social 
issue (Werhane, 2011). We propose that the most promising path is to extend recent work on system perspectives in organization studies (Shipilov \& Gawer, 2020).

\section{Developing a stakeholder systems perspective}

In his classic treatise Metaphysics, Aristotle (1999: 8.6: 1045a) discusses how entities are often formed with properties that extend beyond a simple aggregation of individual parts. Von Bertalanffy (1950) formalized this simple idea into systems theory, defining a system as "a set of elements standing in interrelation among themselves and with the environment." (von Bertalanffy, 1972: 417). He initially applied his insights to account for the functions of biological organisms before extending it to other forms of systems as diverse as computer programs, traffic flows, or economies. The premises of systems theory were particularly useful for explaining organizational and managerial phenomena (Kast \& Rosenzweig, 1972; Parsons, 1951; von Bertalanffy, 1972), culminating in chaos theory and complexity theory (Allen, Maguire, \& McKelvey, 2011; Anderson, 1999; Anderson, Meyer, Eisenhardt, Carley, \& Pettigrew, 1999).

Organizational systems can be understood as arrangements of actors that have purposes but are nonetheless interrelated, coordinating internally and adapting to their environment in order to achieve a central goal (Lai \& Huili Lin, 2017). Beyond organizations, systems thinking has also produced important contributions for business ethics, for example by "circumvent[ing] what often appear to be intractable problems created by systemic constraints for which no individual appears to be responsible" (Werhane, 2002: 33) and by decentering stakeholder analysis (Werhane, 2011).

Importantly, systems thinking is versatile enough to consider collectives of actors at different levels of analysis from the dyad to the entire system - as well as the subsets in between (Kast \& Rosenzweig, 1972; Werhane, 2002). As a consequence (and in contrast to the stakeholder network view) a stakeholder systems perspective considers existing inter- 
organizational arrangements as more than just a set of firm-stakeholder relationships. Systems are by nature adaptive (Werhane, 2008) and therefore have the conceptual bandwidth to simultaneously examine the dynamic properties of both dyadic ties and the overall structure, as well as the recursive relationship between the two.

We define the term "stakeholder system" as a set of actors who perform various roles and functions but collectively mobilize towards the achievement of a larger social goal ${ }^{2}$. A systems approach acknowledges the interplay between dyadic ties and overall structure, enabling us to explore the dynamic of this interplay and consider effectiveness across different levels. In considering both components simultaneously, we can also theorize about how the two aspects co-evolve. Conceptual and methodological limitations have thus far prevented such an examination, despite stakeholder theory being key to understanding the challenges faced by organizations and society (Margolis \& Walsh, 2003).

Considering the abstract nature of stakeholder systems and the potentially limitless number of variables that could be considered to understand them, we turn towards the use of metaphors to select key dimensions. We do not aim at being exhaustive but rather use those dimensions to illustrate the value of a stakeholder systems approach. Metaphors offer some flexibility in our thinking because of the "plurality and openness in meaning" and interpretation they enable (Cornelissen, 2005: 753). Standard theory-building largely draws upon metaphors from natural and social sciences, as well as from the humanities, with some of the most valuable contributions coming from powerful parallels with the performance arts (Biehl, 2017). Thus, we propose that examining the rich artistic material of ballet choreography - through the lens of dance theory - can re-invigorate accounts of stakeholder engagement.

\section{BALLET CHOREOGRAPHY, DANCE THEORY AND STAKEHOLDERS}

\footnotetext{
${ }^{2}$ We are not the first to use the term: Clarkson (1995: 106) uses the term "stakeholder system" without directly defining it.
} 


\section{Motivating the metaphor of dance and ballet choreography}

Given the diversity of systems that exist (von Bertalanffy, 1968), a stakeholder systems view requires a specific metaphor in order for us to demonstrate its generative value. As such, we proceed to explore the potential of dance - and ballet choreographies more specifically - to fill that role. Dance has already been used to explain organizational phenomena: Spencer and Rouse (2014), for instance, explore how creativity and elastic coordination occurs in modern dance groups. With respect to stakeholder dynamics, scholars have drawn passing parallels to dance. The interaction between parties has, for example, been labelled as a 'tango' (Kraan, Hendriksen, van Hoof, van Leeuwen, \& Jouanneau, 2014; Tasselli \& Caimo, 2019): in tandem with stakeholders, the focal organization coordinates and aligns action to produce a form of collective performance.

We propose that this metaphor has the potential to extend stakeholder theory for multiple reasons. Firstly, dance contains temporal patterns such as pacing and rhythm that may be highly relevant for understanding how firms and stakeholders interact (Barnett, 2007; Bowen et al., 1992). As Hanna (1987: 30) observes, dance has a "motor" comprised of elements such as accent (stress/intensity), duration (length of time for movements), meter (grouping of beats/accents) or tempo (rate/speed of sequential movements). Another key distinguishing feature is that choreography is a system where action is purposive and purposeful rather than routine: Kurath (1960: 234) notes that, "out of ordinary motor activities, dance selects, heightens or subdues". Thirdly, dance contains a judgment of aesthetic value that complements the conventional focus on economic value in stakeholder studies (Freeman, et al., 2020): the quality and competence of a dance must be determined by some referent group, which allows for inclusion of norms and values around what stakeholder actions can be considered appropriate. In a broad sense then, choreography informs the coordination of actors in social and physical spaces (Harrison \& Rouse, 2014; Kolo, 2015) thereby offering a fruitful domain of inspiration. 
Ballet specifically is a rich metaphor compared with other forms of dance for generating new conjectures on the dynamics underlying stakeholder systems: the aesthetic value is based on dyadic dependence between dancers - the dance of one individual is affected and affects the movement of others - as well as an overall choreographic arrangement (Hanna, 1987; Kreiner, 2009). More pragmatically, given its cultural hegemony in the West, the various subgenres of ballet have, for better or worse, been explored in dance studies more extensively than other forms such as swing or hip-hop. With ballet, we are therefore furnished with conceptual and empirical material to distinguish highly diverse formats and rules - or lack thereof (Anderson, 2018) - which allows us to contribute to stakeholder theory.

The implications for understanding the dyadic relationships between actors and the dynamic of the system as a whole is not captured by other social systems - even those in the arts. For instance, orchestras may provide insight into characteristics such as harmony and tempo, but how one performer is expected to play is largely pre-defined, with few dyadic exchanges among musicians and no spatial separations. By contrast, choreography acknowledges that the spatial position of actors and their actions are relational to others, and that this apparatus as a whole is what produces aesthetic value. In this sense, ballet offers a "representation that form[s] approximations of the target subject under consideration and that subsequently provide[s] the groundwork for extended theorizing" (Cornelissen, 2006: 1579).

\section{Dance theory as a bridge between the ballet metaphor and stakeholder theory}

Our metaphor (Cornelissen, 2005, 2006) enables us to characterize the dynamics experienced by systems of stakeholders, and the dimensions across which those systems can be compared and understood. The material of ballet choreography provides a unique source that can be transferred towards the target domain of stakeholder theory, thereby enabling a dialogue between dance choreographies and stakeholder theorizing. We propose that dance theory (Hanna, 1987) acts as a bridge, facilitating interpretation of the first domain and its application 
to the second. Specifically, dance theory allows us to interpret and characterize a variety of ballet choreographies, applying those characteristics to understand stakeholder systems.

Dance theory is the body of frameworks to codify, produce and interpret dancing performances (Hanna, 1987). In other terms, it is a "frame of reference" composed of "the laws, forms and power structure" that gives sense to those performances, specifically the articulation between bodily movements, space and narrative (Brandstetter, 2014: 199). Yet, dance theory also emphasizes as much "fluid[ity] and open[ness] in our thinking as possible" (Burt, 2000: 130); there is therefore no formal theorization as we understand it in the field of management, with hypotheses or propositions. Hanna (1987: 187) refers to dance theory as an assessment of aesthetic value, or the appropriateness of what is staged when it involves interpreting characteristics of performances, of what makes them remarkable, and of what connects them. As new concepts and aesthetics have emerged, giving rise to new ways of rendering artistic performances, the evaluation and new ways of appreciating them evolve in parallel, whether for public audiences, architects or performers (Brandstetter, 2014) Nonetheless dance theory, despite its differences with theorization in other fields, is not only for dance scholars but is also targeted at creating a "discursive context" around the dancing praxis (Burt, 2000: 125). It thus serves as a way to label a material practice in order to better understand it, reproduce it and apprehend it in its broader social context.

Dance theory has been used outside the field of cultural production and has found many applications in management science, business and organization studies. Among the most important contributions, the work of Biehl (2017) explores the power of dance theory to derive takeaways for collaboration or unpack relational leadership. A significant body of work bringing together dance theory and organization explores questions of individual embodiment (Slutskaya \& De Cock, 2008). Other pieces explore group interactions: for example, Rowe (2008) uses dance as a metaphor to inform the mechanisms of team learning. Kolo (2015) 
explores the potential contributions of choreography to organizational research noting its focus on the living together in time and space.

\section{Setting the Stage: Ballet and its various subgenres}

Ballet is a performance dance that originated in fifteenth-century Italy before spreading to France and Russia (Homans, 2013; Paskevska, 2005). It combines both music and dance and was initially performed in chambers at royal courts by and for nobles. Strongly influenced by the schools of dance across those different geographies, the richness of ballet stems from a process of striking evolution where subgenres and stylistic approaches branched off without replacing prior styles (Sgourev, 2021). For instance, the emergence of neo-classical and contemporary ballets did not erase the legacy of classical and romantic ballet. Subgenres coexisted, informed each other, and addressed overlapping audiences (Sgourev, 2015). Nowadays, ballet performances usually rely on a set of professional dancers who have undergone expert training, and performances of classical and romantic ballet are still sought after as much as newer subgenres.

We cover a range of seven paradigmatic ballet performances across four subgenres, as outlined in Table 1: classical, romantic, neo-classical and contemporary (Anderson, 2018). We select those performances because they represent a diversity in not just the style of dance, but also the structure and dynamics of choreography. While the different subgenres have borrowed characteristics from each other, the manner in which they combine different attributes in each case produces a distinct style of dance that informs subsequent theorization.

\section{[INSERT TABLE 1 HERE]}

The most well-known type of ballet is also the first to emerge in Italy, France and Russia: the classical ballet. This subgenre is therefore considered traditional and based on an established 
repertoire of movements, choreography and storylines, supported by elaborate costumes and sumptuous sets (Sgourev, 2015). Swan Lake or the Nutcracker are considered as the epitome of classical ballet and are characterized by large ensembles and a rigid narrative structure. The aesthetic value of this sub-genre is derived from the technical execution of moves, with dancer interactions that tend to be frequent and symmetrical (Anderson, 2018).

Romantic ballets on the other hand, despite having numerous overlapping elements with their classical counterparts, are distinct in their focus on the role and the performance of the dancers, with emotions as a source of aesthetic. These ballets emerged in the mid- $19^{\text {th }}$ century, almost two centuries after the first academy of ballet was founded in Paris that formalized classical ballet as a professionalized art (Homans, 2013). As with classical ballets, romantic ballets are driven by linear story-telling and focus on technique, but are distinguished by their emphasis on more episodic interactions between the characters. The Romantic subgenre highlights the prima ballerina, and the narratives often revolve around spirit characters, many of whom are female. La Sylphide is often considered as the first romantic ballet, with a plot revolving around a young Scotsman's infatuation with a forest spirit, and his tumultuous relationships with his fiancée and best friend. Giselle is the second romantic ballet we review and is a story of a woman who is revived by female forest spirits after dying of heartbreak.

With the passage of time, and in the turn of the 1910s, ballet productions started becoming more adventurous and experimental, in particular under the influence of Sergei Diaghilev and the Ballets Russes (Sgourev, 2015). As with many cultural productions during this era, such ballets were expressions of opposition to the romantic movement (Anderson, 2018), and were aimed at reviving and reinterpreting elements from traditional ballet. This new subgenre became known as neo-classical ballet, and included spectacles such as Apollo by George Balanchine, arguably the most well-known neo-classical choreographer. In contrast to romantic ballets, the scenery and the costumes of neo-classical ballets are muted or in some cases absent, while narratives are more abstract and non-linear. The dancers rely more on core 
body movements, with interactions that are physically asymmetric, combined with emergent connections that break away from formalities common in classical and romantic ballets. In such ballets, dancers interact more through continuous opposition than through communion (Paskevska, 2005). In the case of Balanchine's Apollo, the story is oriented on the Greek god Apollo and three muses.

Contemporary ballets, finally, combine elements of classical ballets with more recent aspects of dance derived from jazz and mime (Paskevska, 2005). They also rely on physical performances, but are faster, re-introducing narrative centrality and incorporating acting during the performance. Clytemnestra, by Martha Graham, is thus characterized by energy and borderline violent dance moves, supported at the same time by a conspicuous narrative. The last performance we mobilize is Kenneth McMillan's Isadora, a tribute to the life of dancer Isadora Duncan. Isadora is often seen as an act rather than a ballet, oriented around the life of the dancer and her tumultuous relationships with her partners.

The seven ballets we selected are emblematic of their subgenres; they were dominant at different epochs, yet now co-exist as iconic performances. They capture, in our view, the diversity of ballet choreographies; the striking differences across styles can be used to generate theoretical insights into the nature of stakeholder arrangements, as well as into organizationstakeholder relationships. In the following section, we proceed to translate those key characteristics into multiple dimensions that can apply to stakeholder engagement.

\section{CHARACTERIZING STAKEHOLDER SYSTEMS AS BALLET CHOREOGRAPHY}

In this section, we aim at mobilizing our metaphor to flesh out the key characteristics of the system of ballet, upon which we can theorize the dynamics of a stakeholder arrangement. Through our identification of relevant dance theory work on ballet (Brandstetter, 2014; Burt, 2000; Daly, 1994; Hanna, 1987) and our review of the above-mentioned ballet choreographies, we identify key dimensions of dance performances that revolve around patterning, pace, and 
motion. However, ballet choreography is both about the subjective experience of dancer and the evaluation by audiences (Hanna, 1987); in this sense there are two aspects in the theorization of ballet (Paskevska, 2005) which can be extended to the domain of stakeholder thinking. In contrast with traditional stakeholder thinking that focuses on economic value (Freeman et al., 2020), we consider how aesthetic value - or the appropriateness of what is staged (Kreiner, 2009) - can translate into stakeholder thinking. More specifically, we consider that the appropriateness of a stakeholder system depends on the means and ends of the arrangement in addressing grand challenges (Mena \& Palazzo, 2012; Prell, Hubacek, \& Reed, 2009). We consequently illuminate four major dimensions of dance at two levels, revealing system-level properties of the overall stakeholder systems as well as relational (i.e., dyadic) characteristics between two actors. The metaphor of ballet therefore allows us to simultaneously theorize about dynamics in stakeholder arrangements and relationships. Table 2 presents our interpretation of the structural and dyadic characteristics of the four types of ballet, while Figure 1 distills these into four dimensions.

[INSERT TABLE 2 HERE]

[INSERT FIGURE 1 HERE]

The first two dimensions that emerge from the ballet choreographies relate to the structural characteristics of the stakeholder system. Here, the choreographic elements of the ballet are conceptualized as characteristics of the overall stakeholder arrangement. The remaining dimensions elucidate dynamics at the dyadic level. In this metaphor, the focal firm is taken as a principal dancer, with interactions that occur not only between this dancer and the supporting cast, but also amongst other dancers themselves. Within this metaphor, individual 
stakeholder interactions are seen as a set of dance moves between dyads; from our range of ballet performances, we observe differences in how dancers are expected to interact and interface. Transposed onto the domain of stakeholder systems, this informs the ways we conceptualize stakeholders connecting with each other. Taken together, the four dimensions help us reveal not only the quality of interactions, but also pave the way for understanding how stakeholder systems evolve, adapt and synchronize.

\section{Structural and dyadic characteristics of ballet (and stakeholder) systems}

\section{Structural dimensions}

Polyphonic vs unified narrative: The classical and romantic ballet performances are typically choreographed as a unified narrative, generally oriented around a principal dancer; effectively, this style organizes the rest of the dance troupe and can be readily communicated to the audience. The romantic ballets of La Sylphide and Giselle, for instance, follow the story of a principal female spirit character and their relationships with a human male. Alternatively, neoclassical ballet (in our case, Apollo) relies on a multiplicity of intricate narratives, often in the background, as the performance relies less on a unified plot than on a confluence of distinctive and competing narrative threads. Thus, a dance can also be choreographed as a polyphonic narrative, with a "multiplicity of independent and unmerged voices and consciousnesses... each with equal rights and its own world [that] combine, but do not merge, into the unity of an event" (Bakhtin, 1984: 208). In those pieces, the aesthetic value is derived from following multiple perspectives on the same event.

We conceive these as two ends of the same spectrum: applied to a stakeholder system, this dimension reveals the extent to which multiple stakeholders share a narrative with a focal actor such as a firm. At one end of the spectrum, we have a unified narrative, where the entire stakeholder system approaches an issue from the same perspective, with consensus around definition, diagnosis and/or goals. This can be driven by a focal organization that leads how 
sensemaking occurs around an issue; for instance, Bothello and Mehrpouya (2018) discuss how an NGO named ICLEI created a framing of sustainable urban development that other NGOs eventually adopted. However, a unified narrative can also emerge in the absence of direct ties: Haas (1989, 1992) illustrates how stakeholders mobilized towards regulation of ozonedepleting substances and Mediterranean pollution through similar understandings of cause-andeffect relationships, despite being disconnected from each other.

At the other end of the spectrum, when causal attributions are more complex, multiple divergent perspectives within a stakeholder arrangement can emerge, leading to a polyphonic narrative (Belova, King, \& Sliwa, 2008; Hargrave, 2009). Different pockets of social actors within the stakeholder system perceive an issue differently and their own perspective evolves independently from other narratives. Reinecke and Ansari (2016) highlight how polyphony is endemic to these so-called "wicked problems" as they observe the diverging perspectives of various actors in the context of conflict minerals in Democratic Republic of Congo. These actors not only possess differing ideas of prescriptions to a problem, but also disagree on the diagnosis of the problem itself.

Prompted vs emergent coherence: The second dimension articulates a key aspect common to both choreography and stakeholder systems, namely the motivation that drives the arrangement to coalesce in the first place. Classical and romantic ballets tend to be highly deterministic and scripted; appropriateness is based on technical proficiency, where dancers' moves are programmed and propelled by the narrative. In contrast, the neoclassical and contemporary ballets are based more on an organic evolution rather than on adherence to a scripted routine; the appropriateness of the choreography is contingent upon reactions to and from other characters. For instance, in neoclassical ballets like Apollo or contemporary pieces like Clytemnestra, the appeal of the performance is partly derived from physical and emotional spontaneity, stemming from proximity to other dancers. 
These characteristics inform our second dimension of coherence. While the previous dimension of narrative focuses on the process of ongoing sensemaking and storytelling, coherence is about whether actors are "pushed" or "pulled" together. Applied to stakeholder theory, actors may be pushed together or prompted to form an arrangement, for instance when a crisis threatens to harm both an organization and/or its constituent stakeholders (Pearson \& Clair, 1998). The COVID pandemic, for instance, spurred the creation of the COVAX facility to ensure equitable distribution of coronavirus vaccines, an initiative involving Gavi (an alliance of for-profit vaccine producers), the Coalition for Epidemic Preparedness Innovations (CEPI), and the WHO (McAdams et al., 2020). Alternatively, an arrangement can cohere in the absence of such prompts, forming more organically through common interests that "pull" together to address an important - albeit not necessarily urgent - problem. These emergent stakeholder arrangements can still be facilitated by external actors to catalyze problem-solving: for example, we observe how supranational actors such as the UN play an essential role in “orchestration", creating platforms and fora for stakeholders to self-organize around a specific issue (Abbott \& Snidal, 2010; Andonova \& Levy, 2003). We conceptualize these systems as the other end of the spectrum, where an arrangement coheres in the absence of a shock (Aakhus \& Bzdak, 2015; Allen et al., 2011; Anderson, 1999). This is a common process in the case of MSIs, which usually come together to solve specific issues such as climate change (de Bakker, Rasche, \& Ponte, 2019), even if there is no short-term threat .

The two structural dimensions that we outline above are distinct yet complementary: the narrative dimension captures the evolving discursive aspects of the system, while coherence focuses on the triggers driving the emergence of the system. We observe a range of combinations: A stakeholder system can, for instance, emerge organically without forming a unified narrative: some initiatives around addressing a social issue feature a diversity of frames or viewpoints that do not need to be reconciled over time (Reinecke \& Ansari, 2016). On the other hand, a prompted system can create a unified narrative despite the relevant actors coming 
from diverse backgrounds. Table 3 summarizes the four structural conditions of a stakeholder system and showcases illustrative examples of each.

\section{INSERT TABLE 3 HERE}

\section{Dyadic Dimensions}

In contrast to the first pair of dimensions that focus on structural characteristics, our second pair relates to the dyadic ties between the focal organization (principal dancer) and their related stakeholders (supporting dancers). Contingent on the arrangement, these insights potentially extend to relationships between supporting dancers themselves. In the seven ballet performances we included, we focused on the properties of the interactions between individual dancers. In particular, the "importance of movement (the fact of bodily action) and motion (illusion and residual action resulting from the kind of movement produced)" lies in the way it connects individual performers (Hanna, 1987: 37). Within the discursive space created by the performance (Brandstetter, 2014) the interaction between dancers also signals the balance of power. Such interactions do not only determine the immediate performance but also contribute to the unfolding of the narrative (Burt, 2000; Roulet, 2020). We use dance theory to outline these dimensions, then proceed to apply them to firm-stakeholder relationships as well as to linkages between stakeholders.

Continuous vs episodic interactions: The first of these dimensions is based on the continuity of interactions: relationships may be episodic and sporadic, or they can be continuous. Classical ballets such as the Nutcracker follow the same duo of characters - Clara and the Nutcracker and makes them the focal point of the entire performance. In La Sylphide, the interactions between the main characters - the Sylph and the Scotsman - are more intermittent as they are brought together and taken apart several times throughout the ballet. Part of the aesthetic value of these performances is contingent upon the rhythm, pace and frequency of these interactions. 
By contrast, Clytemnestra and Isadora features a complex web of characters who interact intensely but irregularly with each other.

Similarly, the frequency of firm-stakeholder relationships can be mapped as two ends of a continuum. Episodic interactions of dancers are likely to be ad-hoc, triggered by unpredictable issues that emerge in the relationship and irregularly increase stakeholder urgency (Mitchell et al., 1997), for instance, product recalls or supply chain breakdowns. Accordingly, the episodic nature of these relationships imply transactional and market-based collaborations (Jones et al., 2018), as those episodes usually call for swift resolutions - or at least attempts to do so. At the other end of the continuum, in the same way that two dancers remain entangled for the whole performance, we can imagine firm-stakeholder relationships that are continuous. Those are more likely to be labelled as working relationships (Welcomer et al., 2003) that are stable and consistent over time, often based on norms of mutual reciprocity (Jones et al., 2018).

Symmetric vs asymmetric power: Across the different ballet performances, we consistently observe characters influencing the movement and behavior of others (Daly, 1994). For instance, Clara frees the Nutcracker from a spell, while the Sylph in La Sylphide entrances the Scotsman, drawing him into the forest. By and large though, romantic and classical ballets usually involve highly symmetrical performances with the dancers engaging in reciprocal interactions. By contrast, neo-classical and contemporary ballets often rely on asymmetrical dancing that often includes physical and symbolic dependence; Apollo, for instance, features the main dancer hoisting and holding aloft a muse on his back for several minutes, while in another scene he "grants" space for the muses to take center stage and express themselves in turn.

When transferred to the realm of stakeholder relationships, we argue that this dimension of balance captures the extent to which one party exercises power and influence over another in a relationship (Hillman et al., 2009; Dawkins, 2015), usually through control over crucial material, human, financial and symbolic resources. As Mitchell et al. (1997) note, certain 
stakeholder arrangements may be characterized by power asymmetry that is either firmdominant or stakeholder-dominant, where the actor providing resources uses this ability to control the relationship and dominate decision-making. Yet there also exist instances of firmstakeholder relationships in which both parties are mutually dependent on each other (Ahmadsimab \& Chowdhury, 2021; Ashraf, Ahmadsimab, \& Pinkse, 2017). This symmetry within a relationship usually accompanies a bi-directional sharing of resources.

Taken together, our theorization of the two dimensions of dyadic relationships within stakeholder systems acknowledge and integrate a wider range of relationship dependencies and dynamics beyond what is covered in prior studies (Bundy, Vogel, \& Zachary, 2018). Importantly, the nature of these dyadic characteristics applies to both firm-stakeholder relationships as well as to stakeholder-stakeholder linkages. Our conceptualization therefore does not necessarily consider the firm as the center of the system, but rather as one actor within a larger constellation of actors oriented around a particular issue. Table 4 summarizes the four conditions of dyadic relationships within a system and illustrates those four situations with relevant examples.

\section{INSERT TABLE 4 HERE}

\section{THE DYNAMICS OF STAKEHOLDER SYSTEMS}

In the previous section, we characterized stakeholder systems using two attributes at the structural level (narrative and coherence) and two attributes at the dyadic level (continuity and balance of power). We do not make the case, though, that these are exhaustive - rather, they demonstrate how new analytical dimensions emerge when we reconceptualize stakeholder arrangements using a novel systems metaphor. Yet systems are by nature dynamic (von Bertalanffy, 1972): they transform over time when, for instance, constituent members and their 
relationships with each other change, or when goals evolve (Anderson, 1999; Werhane, 2002); this affects how the arrangement ultimately mobilizes together to collectively solve an issue. In the following section, we build upon our fundamental characteristics to offer a dynamic model exhibiting potential adaptive paths taken by stakeholder systems.

\section{Key assumptions to identify dynamics of stakeholder systems}

Although we distinguish between structural characteristics and dyadic relations of stakeholder arrangements, a systems perspective also highlights how the two sets of dimensions are interrelated. Lawrence, for instance, suggests that influence and force - which are individual level expressions of power - condition and are conditioned by institutional level forms of power such as domination and discipline (Lawrence, 2008). A systemic perspective therefore acknowledges the importance of feedback loops (Levasseur, 2004) as changes in the subpart of the system affects the system as a whole. Conversely, dynamics of the system trigger change at the micro-level. We can imagine the interaction between structural and dyadic dimensions to be recursive: structural dimensions would affect dyadic elements, that would in turn affect structural dimensions, etc. This recursive cycle might well contribute to the disruption of the system, but also potentially its maintenance (Islam, Zyphur, \& Boje, 2008).

Accordingly, we proceed to theorize how the dynamics in structural characteristics and those at the dyad level potentially co-constitute each other. On one hand, dyadic ties are affected by structural characteristics of the overall arrangement - for example, more ties can be created when the overall system is larger. On the other hand, some higher level system characteristics can be derived from the attributes of components interacting (von Bertalanffy, 1972: 411) - this implies that an aggregation of dyadic changes may result in changes to structural characteristics. Although there may be a multitude of potential paths linking structural and dyadic dimensions of stakeholder systems, we focus on what are potentially the most salient connections. Accordingly, the insights we develop below are based on the characteristics of two specific 
dynamics of stakeholder systems. They are not meant to be exhaustive or to capture all potential evolutions of stakeholder systems but to simply illustrate the explanatory power of our model to formulate relevant scenarios.

\section{Illustrating the dynamics of stakeholder systems}

We proceed to highlight two potential dynamic paths that stakeholder systems may take (Figure 2): the first illustrates how structural and dyadic dimensions are interrelated and co-evolve in an emergent system, while the second depicts the same process but in a prompted system. In doing so, we can point to the recursive relationships between dyadic and structural dimensions in our model, while outlining how both evolve over time.

\section{INSERT FIGURE 2 HERE}

In situations of emergent stakeholder systems, stakeholders may be brought together organically through, for instance, shared interests or geographical and political proximity. Initiatives with voluntary participation and proximity in interests and understanding are likely to bring together actors that share at least some common understanding of the issue, indicating a unified narrative at the system level. Early on in such a system, we propose that this results in balanced relationships and continuous interactions. However, this dynamic may not necessarily persist. Numerous studies in the area of private and transnational governance highlight a process where stakeholders convene to address a social or environmental problem, but over time fragment into competing interests with different views of the problem (Bothello \& Mehrpouya, 2018). While this may not necessarily happen, an emergent stakeholder system coupled with a unified narrative may risk a "fragmentation spiral". If the stakeholder system does not converge towards potential solutions, differences between stakeholders' perspectives are more likely to emerge (Gutierrez et al., 2016), leading to the fragmentation of the narrative. 
In turn, such fragmentation is likely to generate imbalance in dyadic relationships, as positions become more entrenched, and interactions become more episodic. Recursively, those degraded dyadic relationships further fragment the narrative into polyphony.

There are several empirical accounts of such a spiral. Fransen $(2011 ; 2015)$ reveals how, for instance, the fragmentation of private sustainability standards in forestry and clothing partially stemmed from regulatory actors that became too stringent; an issue which hints at dyadic power imbalance between the regulator and the regulated. In this situation, we witness a fragmentation spiral triggered by the effect of deteriorating dyadic relationships on structural dimensions of the stakeholder system. Yet the reverse can also occur, where narrative plurality leads to power imbalance: Marquez (2019) demonstrates how transnational governance settings that are highly fragmented can, in some cases, result in regulatory capture by industry and trade associations. This therefore shifts the power balance in dyadic relationships, asymmetrically favoring business interests.

In the case of a prompted system, on the other hand, stakeholders may be cast together (perhaps unwillingly in situations of crises) and obliged to interact and coordinate. Different actors struggle to make sense of the issue or phenomenon, specifically with respect to causeeffect relationships and potential solutions (Reinecke \& Ansari, 2016). In such situations, actors produce different perspectives on a problem and lack the experience of productive dialogue and exchange (Daudigeos et al., 2018). As a result of this plurality of narratives, we expect dyadic relationships to be, at this early stage, episodic and asymmetric; this may in turn reinforce polyphony at a system level.

Over time though, the repeated interactions between stakeholders in this newly formed system may enable mutual learning and thus homogenization - about both the issue at stake and others' perspectives. Hargrave (2009), for instance, discusses how moral imagination can facilitate collective action towards an overarching goal, even among competing interests. As stakeholders coordinate in this prompted system, they may compromise or rethink their initial 
position (Hill \& Jones, 1992), facilitating convergence upon a unified narrative (de Bakker et al., 2019). We argue that recursively, this unified narrative will positively influence stakeholder relationships. First, this will increase the continuity of the relationship as partners develop a common language, perspective and purpose (Mena \& Palazzo, 2012). Second, because of this unifying narrative, stakeholders can learn, coalesce and reorganize themselves to minimize their dependencies and increase their negotiating power (Gutierrez et al., 2016). In turn, those more frequent interactions caused by their embeddedness in a developing system will further the unification of the system's narrative.

This "convergence spiral" is one of the potential dynamics of a prompted stakeholder system. As the stakeholder system is forced into collaboration and suffers from polyphonic narratives, the dyadic level is characterized by episodic interactions, and asymmetric interactions. At this stage, stakeholders necessarily struggle to understand each other's positions and rationales, and what they have to offer to each other. As the narrative becomes more homogenous, and stakeholders learn from each other, interactions become more frequent and more balanced.

An example of this process can be observed in the stakeholder systems that work towards solving climate change (Ansari et al., 2014; Schussler et al., 2014). Ansari et al. (2013), for instance, highlight how a disparate set of actors with distinct logics were brought together to address the problem of climate change. Through a series of field-configuring events, these actors collectively created an overarching consensus of the problem in addition to solutions such as the Kyoto Protocol. Although coming from diverse perspectives, they learned from each other, compromised, and accepted each other's systems of rationality. Thus, they converged towards a unified narrative, also benefitting dyadic relationships, which recursively furthered a common systemic understanding and approach.

\section{DISCUSSION}


Using the metaphor of ballet choreography, we sought to highlight the merits of a systems view of stakeholders. Our stakeholder system theory stresses the importance of simultaneously considering structural dimensions of stakeholder arrangements and dyadic characteristics of stakeholder relationships. Building on the argument that two sets of dimensions recursively affect each other, we illustrated the explanatory power of our model of stakeholder systems: we identified two potential paths for stakeholder systems to evolve, following a fragmentation or a convergence spiral, based on interactions between dyadic and structural dimensions. These are merely meant to map some part of the reality of stakeholder system dynamics, although we also acknowledge the possibility of myriad different directions. The dynamics of stakeholder systems can experience different pathways due to differences in the nature of external jolts (Michaelson \& Tosti-Kharas, 2020), or initial configurations or the specific issue at stake (Bothello \& Salles-Djelic, 2018; Djelic \& Quack, 2007).

We expect that the metaphor of ballet choreography and our characterization of stakeholder systems will open new areas of research and generate useful insights for existing literatures. In particular, our metaphor should further the shift away from a focus on the economic value produced by stakeholder relationships (Freeman et al., 2020), to provide a more encompassing and macro-perspective that assesses the aesthetic value of stakeholders mobilizing towards achieving a goal (Harrison \& Wicks, 2013), specifically in the context of grand challenges (George et al. 2016). By extension, we hope that our systems approach can provide more comprehensive answers to outstanding questions in stakeholder-related research on social responsibility (Margolis \& Walsh, 2003), but also specific phenomena such as multistakeholder initiatives (de Bakker et al., 2019; Mena \& Palazzo, 2012), Cross-Sector Social Partnerships (Ahmadsimab \& Chowdhury, 2021; Ashraf et al., 2017) or transnational standardsetting (Djelic \& Sahlin-Andersson, 2005; Marques, 2019; Reinecke, Manning, \& Von Hagen, 2012). 


\section{From stakeholder dyads and networks to stakeholder systems}

Our framework offers important theoretical implications for stakeholder theory: in elucidating the implications of considering stakeholder arrangements as a system, we complement the stakeholder dyad (Freeman, 1984; Freeman et al., 2010) and network (Rowley, 1997) perspectives that currently underpin much of current stakeholder research. Specifically, we are able to simultaneously incorporate relational and structural aspects of the system (Lawrence, 2008), while highlighting how the two may be interrelated. In this way, we reconcile on one side, a more relational perspective on stakeholders, rooted in behavioral approaches (Bridoux \& Stoelhorst, 2014; 2016) and studies of reciprocity (Boss et al., 2009; Bosse \& Phillips, 2016), with a more structural approach (Cots, 2011; Okazaki et al., 2020). Ultimately, we highlight how a systems perspective can reconceptualize actors as stakeholders of an issue rather than of a firm.

Our argument also proves generative to advance stakeholder analysis, for instance with respect to identification of stakeholders and assessment of their salience (Neville et al., 2011). For instance, from a network perspective, stakeholders that are on the periphery of the network are viewed as marginal (Prell et al., 2009). A systems perspective, on the other hand, illustrates how stakeholders may be disconnected from central actors but may be nonetheless relevant because they share comparable goals and fulfill complementary roles. For example, many “epistemic communities” (Daudigeos, Roulet, \& Valiorgue, 2018; Haas, 1989, 1992) are comprised of stakeholder groups who, despite being fully disconnected from each other, mobilize towards addressing an issue because they share similar narratives (specifically the understanding of cause and effect around a particular issue). A stakeholder systems perspective thus compels us to rethink identification and salience beyond the perspective of the focal organization (cf Mitchell et al., 1997).

Furthermore, approaching stakeholder theory through a systems lens bears important implications with respect to the predictive power of stakeholder analysis. Traditional 
approaches to stakeholder theory focus on the performance of the focal organization (Jones et al., 2018), in other words its ability to satisfy stakeholder demands or its corporate social performance (Margolis \& Walsh, 2003). By contrast, a systemic perspective can help address "grand challenges" whose solutions necessarily involve a multiplicity of stakeholders coordinating with each other, and not only with one focal firm or organization (George et al., 2016; Prell et al., 2009). Theory on multi-stakeholder initiatives (MSI) (Mena \& Palazzo, 2012) already reconceptualizes stakeholders as being concerned with an issue rather than with a firm. We note that our revised focus does not preclude the possibility of examining specific firms as the trigger of issues that bring stakeholders together; rather it provides additional insight into how stakeholders act in concert once an issue becomes salient, irrespective of the source.

Despite this revised focus, a systems perspective nonetheless contains implications for firm strategy. For instance, a key competence for firms is to understand the narrative(s) that drive the actions of different actors (Werhane, 2011), rather than mediating the relationships between stakeholders as is proposed within a network perspective (Roulet \& Pichler, 2020). Firms can also proactively trigger the structuring of a stakeholder system around an issue (de Bakker et al., 2019); in advocating to make an issue salient, firms can also shape the process of emergence and coordination of an entire stakeholder system. For instance, in early international summits following the coining of the term "sustainable development", for-profit actors formed an association called the Business Council for Sustainable Development (BCSD), with a mandate to develop industrial best practices and provide input in environmental policy-making (Bothello \& Salles-Djelic, 2018; Mebratu, 1998). Thus, firms have the capacity to actively structure the stakeholder system through sensemaking activities: i.e., by creating and establishing norms and narratives.

Interestingly, a stakeholder system theory also advances what we could call the macrofoundations of stakeholder theory, rather than its micro-foundations. The micro-foundational perspective on stakeholder theory has already elucidated how stakeholders can be managed 
when they have heterogenous motives (Bridoux \& Stoelhort, 2014), e.g. when stakeholders favor fairness and reciprocity. A macro-perspective zooms out to the arrangement as a whole, rather than focusing on its subparts. Such approach allows us to consider the links between stakeholders (e.g., how they may influence each other) based on different roles and functions within the overall structure. In a macro-foundational perspective, the focus is how firms' behavior can be enabled and constrained by their stakeholder system - and not only by individual stakeholder influences (Frooman, 1999).

Finally, our metaphor of dance also allows us to contribute to the literature on organizational systems, which has been the subject of revived interest in recent years (Shipilov \& Gawer, 2020). By using the metaphor of dance, we introduce novel elements to the study of systems, such as pacing and rhythm (e.g. episodic vs. continuous interaction) that can be fruitful for understanding how firms and stakeholders interact (Barnett, 2007; Bowen et al., 1992). Furthermore, through our distinction of "prompted" vs. "emergent" systems, we also provide a basis for understanding which systems form through external triggers and which coalesce through their internal properties. Thirdly, dance contains a judgment of value that is missing from other forms of system: a ballet is considered aesthetically appropriate in some combinations of system features but not others. This is what Hanna (1987) calls aesthetic value - a judgment of the appropriateness of the arrangement (Kreiner, 2009). Systemic perspectives can benefit from going beyond considering only economic value, but instead consider the value produced by the system for society in a broader sense. We can therefore point to novel elements of systems that have thus far been overlooked. We do not however, claim that ballet is the only system that can elucidate these dynamics; it is but one system that is generative of stakeholder system insights.

\section{Limitations and future research avenues}


The two structural and the two dyadic dimensions of our models could also be perceived as limiting the potential of our metaphor. To some extent, the choice of the characteristics of stakeholder systems we put forward in this theoretical piece might be circumscribing the dynamics we can theorize about. Future research could flesh out different characteristics of stakeholder systems - to go beyond what could be seen as simplifying binary contrasts in our current model - by further taking advantage of the rich literature on system dynamics. This also shapes potential pathways to change that can occur in stakeholder systems. As previously pointed out, the dynamics of stakeholder systems that we identify only cover parts of a broad and complex phenomenon. Future research could further explore the dynamics of stakeholder systems, by identifying alternative pathways, depending on the issues at stake.

Furthermore, the choice of ballet for our metaphor could be criticized for offering too much of a western lens on stakeholder theory, and also because ballet is often seen as cultural products for the elites. However, neo-classical and contemporary ballets have deviated quite significantly from elitist canons, tastes and modes of consumption of their predecessors, as they relate far more to modern dancing and more recent genres of music. Future research could bring in more music- or dance-related metaphors: Jazz, for example, has been commonly used as a metaphor for organization (Lewin, 1998). Existing work has also recognized the importance of dance as not only a fruitful metaphor but also a methodological tool for organization studies (Biehl, 2017). While the metaphor of ballet is a plausible one (Cornelissen, 2005; 2006), we could consider other potential metaphors that could be explored to further stakeholder system theory.

\section{Practical implications: Organizing as a system}

We believe that a systems level view on how organizations engage with stakeholders has practical implications towards enabling positive social change and addressing grand challenges (Greenwood, 2007). For managers, we argue that a systems view facilitates an acknowledgment 
that the firm may not be the hub or central node in problem-solving around a specific challenge (Werhane, 2011). Rather, it emphasizes the idea that businesses have particular contributions to make which, despite being necessary, may not be sufficient for tackling large-scale and pervasive social and environmental problems (Roulet \& Bothello, 2020). This entails the important recognition that other actors have roles and responsibilities in addressing an issue, as well as unique resources that cannot be offered by firms. Such complementarities among different actors are a crucial aspect of a systems-based view and reinforces the need for managers to strengthen - rather than substitute for - relationships with other actors in their environment. Our approach also suggests that third parties might orchestrate those systems, and coordinate different parties, align the interest of different actors, and spread information (Berkowitz et al., 2020).

Beyond this, our specific metaphor of ballet also contains managerial implications. Our image encourages awareness of how the structural and dyadic characteristics between firms and their stakeholders are interwoven and dynamic; for instance, relational traits such as resource dependence are not fixed but evolve over time. Importantly, this evolution has an assessment of appropriateness by different organizational audiences. Specifically, managers should be aware that their interactions with stakeholders do not only contain functional qualities but are judged according to aesthetic standards by different actors. Finally, the general management of organizations can benefit from the metaphor of dancing (cf. Harrison \& Rouse, 2014) in particular to think about collaboration as harmonious coordination.

\section{CONCLUSION}

In this article, we sought to establish the first pillars of a "stakeholder system theory", using dance theory and the metaphor of ballet. The structural and dyadic dimensions of stakeholder systems complement existing characterizations in stakeholder theory, whether the hub and spoke model of firm-stakeholder relationships (Bundy et al., 2018) or more recent network 
perspectives (Rowley, 1997). The metaphor that we provide helps overcome some limitations of existing stakeholder frameworks, namely considering structural and dyadic aspects in isolation from each other, and thus limiting our ability to theorize the dynamic and adaptive aspects of stakeholder systems.

Our perspective also departs from a focus on stakeholders of a firm, to consider stakeholders of an issue (Saffer, 2019). We have sought to shift the debate away from stakeholder frameworks that focus on a central firm and its relationships with its constituents. Such accounts are based on specific conceptual premises that unduly ignore important considerations, such as the goal of the overall arrangement or the frequency of interactions. These perspectives are also ill-suited to simultaneously consider the structural and dyadic levels of analysis, as well their co-evolution. To overcome those limitations, we brought in the metaphor of ballet choreography, building on the analysis of seven iconic performances across four subgenres. We used dance theory as a bridge to identify the key characteristics of those performances that could subsequently be translated into the stakeholder domain. Our resulting framework reconceptualizes stakeholder arrangements as "stakeholder systems", in other words a set of social actors attempting to address a particular issue. We aim for this metaphor and our resulting model to feed future research on grand challenges, and how public and private actors coordinate to address environmental and social issues.

\section{REFERENCES}

Aakhus, M., \& Bzdak, M. 2015. Stakeholder engagement as communication design practice. Journal of Public Affairs, 15(2): 188-200.

Abbott, K. W. 2012. Engaging the public and the private in global sustainability governance. International Affairs, 88(3): 543-564.

Abbott, K. W. 2013. Strengthening the Transnational Regime Complex for Climate Change. Transnational Environmental Law, 3(01): 57-88.

Abbott, K. W., \& Snidal, D. 2010. International regulation without international government: Improving IO performance through orchestration. The Review of International Organizations, 5(3): 315-344.

Adner, R. 2017. Ecosystem as Structure: An Actionable Construct for Strategy. Journal of Management, 43(1): 39-58. 
Ahmadsimab, A., \& Chowdhury, I. 2021. Managing Tensions and Divergent Institutional Logics in Firm-NPO Partnerships. Journal of Business Ethics, 168(3): 651-670.

Allen, P., Maguire, S., \& McKelvey, B. 2011. The SAGE handbook of complexity and management. Thousand Oaks, CA: SAGE Publications.

Anderson, J. 2018. Ballet \& modern dance: a concise history. Princeton, NJ: Princeton Book Company.

Anderson, P. 1999. Perspective: Complexity Theory and Organization Science. Organization Science, 10(3): 216-232.

Anderson, P., Meyer, A., Eisenhardt, K., Carley, K., \& Pettigrew, A. 1999. Introduction to the Special Issue: Applications of Complexity Theory to Organization Science. Organization Science, 10(3): 233-236.

Andonova, L. B., \& Levy, M. A. 2003. Franchising global governance: making sense of the Johannesburg type II partnerships. Yearbook of International Co-Operation on Environment and Development, (January): 19-32.

Ansari, S. M., Wijen, F., \& Gray, B. 2013. Constructing a Climate Change Logic : An Institutional Perspective on the " Tragedy of the Commons ." Organization Science, 24(4): 1-27.

Archer, M. 1995. Realist Social Theory: The morphogenetic approach. Cambridge, UK: Cambridge University Press.

Aristotle. 1999. Metaphysics [translated by Joe Sachs]. Santa Fe, NM: Green Lion Press.

Ashraf, N., Ahmadsimab, A., \& Pinkse, J. 2017. From Animosity to Affinity: The Interplay of Competing Logics and Interdependence in Cross-Sector Partnerships. Journal of Management Studies, 54(6): 793-822.

Bakhtin, M. M. 1984. Problems of Dostoevsky's poetics. Minneapolis, MN: University of Minnesota Press.

Bansal, P., Grewatsch, S., \& Sharma, G. 2021. How COVID-19 informs business sustainability research: It's time for a systems perspective. Journal of Management Studies, 58(2), 602-606.

Barley, S. R., \& Tolbert, P. S. 1997. Institutionalization and Structuration: Studying the Links between Action and Institution. Organization Studies, 18(1): 93-117.

Barnett, M. L. 2007. Stakeholder influence capacity and the variability of financial returns to corporate social responsibility. Academy of Management Review, 32(3): 794-816.

Beelitz, A., \& Merkl-Davies, D. M. 2019. Discursive framing in private and public communication by pro-nuclear corporate, political and regulatory actors following the Fukushima disaster. Accounting, Auditing and Accountability Journal, 32(5): 15851614.

Belova, O., King, I., \& Sliwa, M. 2008. Introduction: Polyphony and organization studies: Mikhail Bakhtin and beyond. Organization Studies, 29(04): 493-500.

Biehl, B. 2017. Dance and Organization: Integrating Dance Theory and Methods into the Study of Management. New York, NY: Routledge.

Bitektine, A., Haack, P., Bothello, J., \& Mair, J. 2019. Inhabited actors: Internalizing institutions through communication and actorhood models. Journal of Management Studies.

Bothello, J., \& Mehrpouya, A. 2018. Between regulatory field structuring and organizational roles: Intermediation in the field of sustainable urban development. Regulation \& Governance, (July): 1-20.

Bothello, J., \& Salles-Djelic, M.-L. 2018. Evolving Conceptualizations of Organizational Environmentalism: A Path Generation Account. Organization Studies, 39(1): 93-119.

Bowen, R. M., Johnson, M. F., Shevlin, T., \& Shores, D. 1992. Determinants of the Timing of Quarterly Earnings Announcements. Journal of Accounting, Auditing \& Finance, 7(4): 395-422. 
Brandstetter, G. 2014. Dis/Balances. Dance and Theory. Bielefeld, Germany: Transcript.

Bridoux, F., \& Stoelhorst, J. W. 2016. Stakeholder Relationships and Social Welfare: A Behavioral Theory of Contributions to Joint Value Creation. Academy of Management Review, 41(2): 229-251.

Bridoux, F., \& Stoelhort, J. W. 2014. Microfoundations for stakeholder theory: Managing stakeholders with heterogeneous motives. Strategic Management Journal, 35(1): 107125.

Bundy, J., Vogel, R. M., \& Zachary, M. A. 2018. Organization-stakeholder fit: A dynamic theory of cooperation, compromise, and conflict between an organization and its stakeholders. Strategic Management Journal, 39(2): 476-501.

Burt, R. 2000. Dance Theory, Sociology, and Aesthetics. Dance Research Journal, 32(1): $125-131$.

Clarkson, M. E. 1995. A Stakeholder Framework for Analyzing and Evaluating Corporate Social Performance. Academy of Management Review, 20(1): 92-117.

Cornelissen, J. P. 2005. Beyond Compare: Metaphor In Organization Theory. Academy of Management Review, 30(4): 751-764.

Cornelissen, J. P. 2006. Making Sense of Theory Construction: Metaphor and Disciplined Imagination. Organization Studies, 27(11): 1579-1597.

Cornelissen, J., Höllerer, M. A., \& Seidl, D. 2021. What Theory Is and Can Be: Forms of Theorizing in Organizational Scholarship. Organization Theory, 2(3), 26317877211020328.

Cots, E. G. 2011. Stakeholder social capital: a new approach to stakeholder theory. Business Ethics: A European Review, 20(4): 328-341.

Daly, A. 1994. Isadora Duncan's Dance Theory. Dance Research Journal, 26(2): 24-31.

Daudigeos, T., Roulet, T., \& Valiorgue, B. 2018. How Scandals Act as Catalysts of Fringe Stakeholders' Contentious Actions Against Multinational Corporations. Business and Society. https://doi.org/10.1177/0007650318756982.

Dawkins, C. 2015. Agonistic Pluralism and Stakeholder Engagement. Business Ethics Quarterly, 25(1): 1-28.

de Bakker, F. G. A., Rasche, A., \& Ponte, S. 2019. Multi-Stakeholder Initiatives on Sustainability: A Cross-Disciplinary Review and Research Agenda for Business Ethics. Business Ethics Quarterly, 29(03): 343-383.

Djelic, M.-L., \& Quack, S. 2007. Overcoming path dependency: Path generation in open systems. Theory and Society, 36(2): 161-186.

Djelic, M.-L., \& Sahlin-Andersson, K. 2005. Transnational Governance in the making Regulatory Fields and their, 1-47.

Etchanchu, H. 2017. How Institutions Matter For Frame Amplification: Framing Shale Gas Related to an Energy Transition. Academy of Management Proceedings, 2017(1): 12051.

Fransen, L. 2011. Why Do Private Governance Organizations Not Converge? A PoliticalInstitutional Analysis of Transnational Labor Standards Regulation. Governance, 24(2): 359-387.

Fransen, L., \& Conzelmann, T. 2015. Fragmented or cohesive transnational private regulation of sustainability standards? A comparative study. Regulation \& Governance, 9(3): 259275.

Freeman, R. E. 1984. Strategic Management: A Stakeholder Approach. Boston, MA: Pitman.

Freeman, R. E., Harrison, J. S., Wicks, A. C., Parmar, B. L., \& De Colle, S. 2010. Stakeholder theory: The state of the art. Cambridge, UK: Cambridge University Press.

Freeman, R. E., Harrison, J. S., \& Zyglidopoulos, S. 2018. Stakeholder Theory: Concepts and Strategies. Cambridge, UK: Cambridge University Press.

Frooman, J. 1999. Stakeholder Influence Strategies. Academy of Magagement Review, 24(2): $191-205$. 
George, G., Howard-Grenville, J., Joshi, A., \& Tihanyi, L. 2016. Understanding and Tackling Societal Grand Challenges through Management Research. Academy of Management Journal, 59(6): 1880-1895.

Girard, C., \& Sobczak, A. 2012. Towards a Model of Corporate and Social Stakeholder Engagement: Analyzing the Relations Between a French Mutual Bank and Its Members. Journal of Business Ethics, 107(2): 215-225.

Greenwood, M. 2007. Stakeholder Engagement: Beyond the Myth of Corporate Responsibility. Journal of Business Ethics, 74(4): 315-327.

Gutiérrez, R., Márquez, P., \& Reficco, E. 2016. Configuration and Development of Alliance Portfolios: A Comparison of Same-Sector and Cross-Sector Partnerships. Journal of Business Ethics, 135(1): 55-69.

Haas, P. M. 1989. Do regimes matter? Epistemic communities and Mediterranean pollution control. International Organization, 43(3): 377-403.

Haas, P. M. 1992. Banning chlorofluorocarbons: epistemic community efforts to protect stratospheric ozone. International Organization, 46(01): 187.

Hanna, J. L. 1987. To dance is human: A theory of nonverbal communication. Chicago, IL: University of Chicago Press.

Hargrave, T. J. 2009. Moral Imagination, Collective Action, and the Achievement of Moral Outcomes. Business Ethics Quarterly, 19(1): 87-104.

Harrison, S. H., \& Rouse, E. D. 2014. Let's dance! Elastic coordination in creative group work: A qualitative study of modern dancers. Academy of Management Journal, 57(5): 1256-1283.

Harrison, J. S., \& Wicks, A. C. 2013. Stakeholder theory, value, and firm performance. Business ethics quarterly, 97-124.

Hein, A. M., Jankovic, M., Feng, W., Farel, R., Yune, J. H., et al. 2017. Stakeholder power in industrial symbioses: A stakeholder value network approach. Journal of Cleaner Production, 148: 923-933.

Hillman, A. J., Withers, M. C., \& Collins, B. J. 2009. Resource Dependence Theory: A Review. Journal of Management, 35(6): 1404-1427.

Homans, J. 2013. Apollo's angels: A history of ballet. New York, NY: Random House.

Islam, G., Zyphur, M. J., \& Boje, D. 2008. Carnival and spectacle in Krewe de Vieux and the Mystic Krewe of Spermes: The mingling of organization and celebration. Organization Studies, 29(12): 1565-1589.

Jones, T. M., Harrison, J. S., \& Felps, W. 2018. How Applying Instrumental Stakeholder Theory Can Provide Sustainable Competitive Advantage. Academy of Management Review, 43(3): 371-391.

Kast, F. E., \& Rosenzweig, J. E. 1972. General systems theory: Applications for organization and management. Academy of Management Journal, 15(4): 447-465.

Ketokivi, M., Mantere, S., \& Cornelissen, J. 2017. Reasoning by analogy and the progress of theory. Academy of Management Review, 42(4): 637-658.

Kilduff, M., \& Brass, D. J. 2010. Organizational social network research: Core ideas and key debates. Academy of Management Annals, 4(1): 317-357.

Kolo, K. 2015. Ode to Choreography. Organizational Aesthetics, 5(1): 37.

Kraan, M., Hendriksen, A., van Hoof, L., van Leeuwen, J., \& Jouanneau, C. 2014. How to dance? The tango of stakeholder involvement in marine governance research. Marine Policy, 50: 347-352.

Kurath, G. P. 1960. Panorama of Dance Ethnology. Current Anthropology, 1(3): 233-254.

Lai, C., \& Huili Lin, S. 2017. Systems Theory. In C. R. Scott \& L. Lewis (Eds.), The International Encyclopedia of Organizational Communication: 1-18. Wiley.

Lawrence, T. B. 2008. Power, institutions and organizations. In R. Greenwood, C. Oliver, K. Sahlin-Andersson, \& R. Suddaby (Eds.), The SAGE Handbook of Organizational 
Institutionalism: 170-197. Thousand Oaks, CA: SAGE Publications Inc.

Levasseur, R. F. 2004. Open System Theory and Organizations. Futurics, 28(1/2): 79-85.

Lewin, A. Y. 1998. Introduction-Jazz Improvisation as a Metaphor for Organization Theory. Organization Science, 9(5): 539-539.

Margolis, J. D., \& Walsh, J. P. 2003. Misery Loves Companies: Rethinking Social Initiatives by Business. Administrative Science Quarterly, 48(2): 268-305.

Marques, J. C. 2019. Private regulatory capture via harmonization: An analysis of global retailer regulatory intermediaries. Regulation and Governance, 13(2): 157-176.

McAdams, D., McDade, K. K., Ogbuoji, O., Johnson, M., Dixit, S., et al. 2020. Incentivising wealthy nations to participate in the COVID-19 Vaccine Global Access Facility (COVAX): A game theory perspective. BMJ Global Health, 5(11): 1-7.

Mebratu, D. 1998. Sustainability and Sustainable Development: Historical and Conceptual Review. Environmental Impact Assessment Review, 18(6): 493-520.

Mena, S., \& Palazzo, G. 2012. Input and Output Legitimacy of Multi-Stakeholder Initiatives. Business Ethics Quarterly, 22(3): 527-556.

Michaelson, C., \& Tosti-Kharas, J. 2020. A world changed: What post-9/11 stories tell us about the position of America, purpose of business, and meaning of work. Academy of Management Review, 45(4): 877-895.

Mitchell, R. K., Agle, B., \& Wood, D. J. 1997. Toward a Theory of Stakeholder Identification and Salience : Defining the Principle of Who and What Really Counts. Academy of Management Review, 22(4): 853-886.

Moog, S., Spicer, A., \& Böhm, S. 2015. The Politics of Multi-Stakeholder Initiatives: The Crisis of the Forest Stewardship Council. Journal of Business Ethics, 128(3): 469-493.

Nehrt, C. 1996. Timing and Intensity Effects of Environmental Investments. Strategic Management Journal, 17(7): 535-547.

Neville, B. A., Bell, S. J., \& Whitwell, G. J. 2011. Stakeholder Salience Revisited: Refining, Redefining, and Refueling an Underdeveloped Conceptual Tool. Journal of Business Ethics, 102(3): 357-378.

Okazaki, S., Plangger, K., Roulet, T., \& Menéndez, H. D. 2020. Assessing stakeholder network engagement. European Journal of Marketing. https://doi.org/10.1108/EJM-122018-0842.

Ostrom, E. 2010. Beyond Markets and States: Polycentric Governance of Complex Economic Systems. American Economic Review, 100(June): 641-672.

Parsons, T. 1951. The Social System. London, UK: Routledge.

Paskevska, A. 2005. Ballet beyond tradition. London, UK: Routledge.

Pearson, C. M., \& Clair, J. A. 1998. Reframing Crisis Management. Academy of Management Review, 23(1): 59-76.

Prell, C., Hubacek, K., \& Reed, M. 2009. Stakeholder Analysis and Social Network Analysis in Natural Resource Management. Society \& Natural Resources, 22(6): 501-518.

Rasche, A. 2012. Global Policies and Local Practice: Loose and Tight Couplings in MultiStakeholder Initiatives. Business Ethics Quarterly, 22(4): 679-708.

Reinecke, J., \& Ansari, S. 2016. Taming Wicked Problems: The Role of Framing in the Construction of Corporate Social Responsibility. Journal of Management Studies, 53(3): 299-329.

Reinecke, J., Manning, S., \& Von Hagen, O. 2012. The emergence of a standards market: Multiplicity of sustainability standards in the global coffee industry. Organization Studies, 33(5-6): 791-814.

Roulet, T. J. 2020. The Power of Being Divisive: Understanding Negative Social Evaluations. Stanford, CA: Stanford University Press.

Roulet, T., \& Bothello, J. 2020. Why “de-growth" shouldn't scare businesses. Harvard Business Review, 14. 
Roulet, T. J., \& Pichler, R. 2020. Blame Game Theory: Scapegoating, Whistleblowing and Discursive Struggles following Accusations of Organizational Misconduct. Organization Theory, 1(4), 2631787720975192.

Rowe, A. 2008. Unfolding the Dance of Team Learning: A Metaphorical Investigation of Collective Learning. Management Learning, 39(1): 41-56.

Rowley, T. J. 1997. Moving beyond Dyadic Ties: A Network Theory of Stakeholder Influences. Academy of Management Review, 22(4): 887-910.

Saffer, A. J. 2019. Fostering social capital in an international multi-stakeholder issue network. Public Relations Review, 45(2): 282-296.

Schilling, M. A. 2000. Decades ahead of her time: advancing stakeholder theory through the ideas of Mary Parker Follett. Journal of Management History, 6(5): 224-242.

Sgourev, S. V. 2015. Brokerage as Catalysis: How Diaghilev's Ballets Russes Escalated Modernism. Organization Studies, 36(3): 343-361.

Sgourev, S. V. 2021. Categorical Bifurcation: The Rite of Spring at the Threshold of Modernism. Cultural Sociology, 15(2), 292-310.

Shipilov, A., \& Gawer, A. 2020. Integrating research on interorganizational networks and ecosystems. Academy of Management Annals, 14(1): 92-121.

Shymko, Y., \& Roulet, T. J. 2017. When does medici hurt da vinci? Mitigating the signaling effect of extraneous stakeholder relationships in the field of cultural production. Academy of Management Journal, 60(4): 1307-1338.

Slutskaya, N., \& De Cock, C. 2008. The Body Dances: Carnival Dance and Organization. Organization, 15(6): 851-868.

Tantalo, C., \& Priem, R. L. 2016. Value creation through stakeholder synergy. Strategic Management Journal, 37: 314-329.

Tasselli, S., \& Caimo, A. 2019. Does it take three to dance the Tango? Organizational design, triadic structures and boundary spanning across subunits. Social Networks, 59: 10-22.

Van de Ven, A. H. 1975. On the Nature, Formation, and Maintenance of Relations Among Organizations. Academy of Management Review, 1(4): 24-36.

von Bertalanffy, L. 1950. The theory of open systems in physics and biology. Science, 11(2872): 23-29.

von Bertalanffy, L. 1968. General system theory: Foundations, development, applications. New York, NY: Braziller.

von Bertalanffy, L. 1972. The History and Status of General Systems Theory. Academy of Management Journal, 15(4): 407-426.

Welcomer, S. A., Cochran, P. L., Rands, G., \& Haggerty, M. 2003. Constructing a Web. Business \& Society, 42(1): 43-82.

Werhane, P. H. 2002. Moral Imagination and Systems Thinking. Journal of Business Ethics, 38(1/2): 33-42.

Werhane, P. H. 2008. Mental models, moral imagination and system thinking in the age of globalization. Journal of Business Ethics, 78(3): 463-474.

Werhane, P. H. 2011. Globalization, mental models and decentering stakeholder approaches. In R. Phillips (Ed.), Stakeholder Theory: Impact and Prospects: 111-129. Cheltenham, UK. 
TABLE AND FIGURES

Table 1 - Summary of ballets

\begin{tabular}{c|l|l|l|l} 
Subgenre & Classical & Romantic & Neo-Classical & Contemporary \\
\hline \hline Illustration & Swan Lake, & La Sylphide, & Apollo & Clytemnestra, \\
& The Nutcracker & Giselle & & Isadora
\end{tabular}


Table 2 - Subgenres of ballet and characteristics of systems

\begin{tabular}{c|l|l|l|l} 
Subgenre & Classical & Romantic & Neo-Classical & Contemporary \\
\hline \hline $\begin{array}{c}\text { Structural } \\
\text { aspects }\end{array}$ & $\begin{array}{l}\text { Unified } \\
\text { narrative, } \\
\text { prompted } \\
\text { coherence. }\end{array}$ & $\begin{array}{l}\text { Unified } \\
\text { narrative, } \\
\text { prompted } \\
\text { coherence }\end{array}$ & $\begin{array}{l}\text { Polyphonic } \\
\text { narrative; } \\
\text { emergent } \\
\text { coherence }\end{array}$ & $\begin{array}{l}\text { Unified } \\
\text { narrative; } \\
\text { emergent } \\
\text { coherence }\end{array}$ \\
\hline $\begin{array}{l}\text { Dyadic } \\
\text { aspects }\end{array}$ & $\begin{array}{l}\text { Symmetrical } \\
\text { movements; } \\
\text { continuous } \\
\text { interaction. }\end{array}$ & $\begin{array}{l}\text { Symmetrical } \\
\text { movements; } \\
\text { episodic } \\
\text { interaction }\end{array}$ & $\begin{array}{l}\text { Asymmetrical } \\
\text { movements; } \\
\text { continuous } \\
\text { interactions }\end{array}$ & $\begin{array}{l}\text { Asymmetrical } \\
\text { movements; } \\
\text { episodic } \\
\text { interactions }\end{array}$
\end{tabular}




\begin{tabular}{|c|c|c|}
\hline $\begin{array}{c}\text { Polyphonic } \\
\text { narrative }\end{array}$ & $\begin{array}{l}\text { The stakeholder system is quickly } \\
\text { propelled by a pressing issue, but } \\
\text { stakeholders perceive and frame the } \\
\text { issue in divergent ways. }\end{array}$ & $\begin{array}{l}\text { The stakeholder system grows } \\
\text { organically around an issue, but } \\
\text { despite aggregation, stakeholders } \\
\text { have different diagnoses and } \\
\text { prognoses of the issue. }\end{array}$ \\
\hline $\begin{array}{c}\text { Illustrative } \\
\text { Example }\end{array}$ & $\begin{array}{l}\text { Bothello \& Salles-Djelic (2018) } \\
\text { show how the Brundtland Report } \\
\text { triggers modern ecologism, but } \\
\text { proponents are divided on whether } \\
\text { nature is an exploitable resource or } \\
\text { whether it has intrinsic value. }\end{array}$ & $\begin{array}{l}\text { Etchanchu (2017) shows that the } \\
\text { growing use of shale gas is framed } \\
\text { by some countries as a transition } \\
\text { fuel, by some as a way to achieve } \\
\text { energy security, and by others as an } \\
\text { environmental disaster. }\end{array}$ \\
\hline $\begin{array}{c}\text { Unified } \\
\text { narrative }\end{array}$ & $\begin{array}{l}\text { The stakeholder system is quickly } \\
\text { propelled by a pressing issue, but } \\
\text { this issue is framed in a coherent } \\
\text { way across stakeholders. }\end{array}$ & $\begin{array}{l}\text { The stakeholder system grows } \\
\text { organically around an issue, but } \\
\text { there is consensus around the } \\
\text { framing of the issue. }\end{array}$ \\
\hline $\begin{array}{l}\text { Illustrative } \\
\text { Example }\end{array}$ & $\begin{array}{l}\text { Beelitz \& Merkl-Davis (2019) reveal } \\
\text { how, following the Fukushima } \\
\text { disaster, corporate, political and } \\
\text { regulatory actors in the UK } \\
\text { assembled to defend nuclear energy } \\
\text { and prevent a public controversy. }\end{array}$ & $\begin{array}{l}\text { Ansari et al. (2013) document the } \\
\text { process by which a transnational } \\
\text { community builds a working } \\
\text { consensus around a "climate } \\
\text { change logic" to avoid a tragedy of } \\
\text { the commons effect. }\end{array}$ \\
\hline
\end{tabular}




\begin{tabular}{|c|c|c|}
\hline Continuous & $\begin{array}{l}\text { The two actors are collaborating } \\
\text { repeatedly and remain in constant } \\
\text { contact. They need each other and the } \\
\text { relationship is mutually beneficial. }\end{array}$ & $\begin{array}{l}\text { The two actors are regularly working } \\
\text { hand in hand but one of them is more } \\
\text { important to the other and to the } \\
\text { relationship. }\end{array}$ \\
\hline $\begin{array}{c}\text { Illustrative } \\
\text { Example }\end{array}$ & $\begin{array}{l}\text { Ashraf et al. (2017) illustrate how } \\
\text { firm-NPO partnerships in the carbon- } \\
\text { offset market have higher survival } \\
\text { rates when they are mutually } \\
\text { dependent on each other. }\end{array}$ & $\begin{array}{l}\text { Ahmadsimab \& Chowdhury } \\
\text { (Ahmadsimab \& Chowdhury, 2021) } \\
\text { show close working relationships in } \\
\text { Carrefour-FIDH and P\&G-UNICEF } \\
\text { partnerships, although marked by } \\
\text { early power imbalances. }\end{array}$ \\
\hline Episodic & $\begin{array}{l}\text { The two actors work together } \\
\text { irregularly but have a mutual interest } \\
\text { and complementary resources. }\end{array}$ & $\begin{array}{l}\text { The more dependent actor has to } \\
\text { nudge the more powerful one to } \\
\text { intervene. After each episode, the } \\
\text { relationship stretches thin again. }\end{array}$ \\
\hline $\begin{array}{l}\text { Illustrative } \\
\text { Example }\end{array}$ & $\begin{array}{l}\text { Bowen et al. (1992) discuss how firms } \\
\text { engage with stakeholders episodically } \\
\text { through quarterly announcements; the } \\
\text { timing is based on mitigating negative } \\
\text { reputational effects of bad news. }\end{array}$ & $\begin{array}{l}\text { Gutierrez et al. (2016) reveal how } \\
\text { firms opportunistically enter } \\
\text { partnerships with NGOs to reduce } \\
\text { risk at the Bottom of the Pyramid, } \\
\text { but then dissolve the partnerships. }\end{array}$ \\
\hline
\end{tabular}


Figure 1: Transposing dimensions from ballet to stakeholder systems

\section{Structural dimensions}

\begin{tabular}{|c|c|c|}
\hline Polyphonic & Narrative & Unified \\
\hline Prompted & Coherence & Emergent \\
\hline
\end{tabular}

\section{Dyadic dimensions}

\begin{tabular}{|c|c|c|}
\hline Continuous & Interactions & Episodic \\
\hline Symmetrical & Balance & Asymmetrical \\
\hline
\end{tabular}


Figure 2: Potential dynamic paths in stakeholder systems

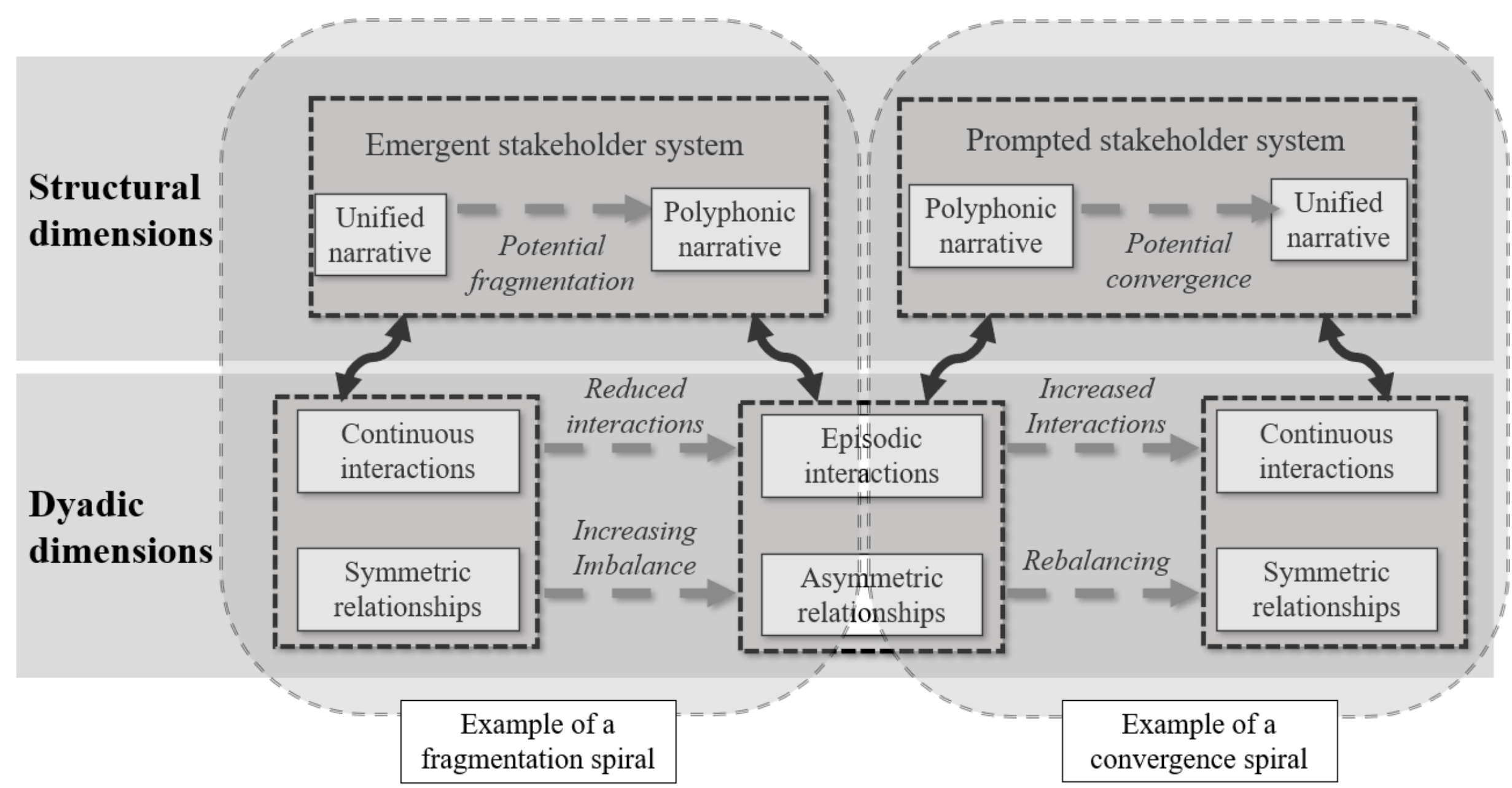


